\title{
Repeat colonoscopy after a colonoscopy with a negative result in Ontario: a population-based cohort study
}

\author{
Lieke Hol MD PhD, Rinku Sutradhar PhD, Sumei Gu MSc, Nancy N. Baxter MD PhD, \\ Linda Rabeneck MD MPH, Jill M. Tinmouth MD PhD, Lawrence F. Paszat MD MSc; \\ the investigators of the Ontario Cancer Screening Research Network
}

\section{Abstract}

Background: Data suggest the overuse of repeat colonoscopies, especially in patients at low risk for colorectal cancer. Our objective was to evaluate the time to repeat colonoscopies in low-risk patients aged 50-79 years old and the associated patient- and endoscopistrelated factors.

Methods: All patients aged 50-79 years of age who underwent a complete outpatient colonoscopy with a negative result between 2000 and 2007 were identified from the Ontario Health Insurance Plan database. A colonoscopy performed within 5.5 years of follow-up after the index colonoscopy was considered an early repeat colonoscopy. Patient, endoscopist and endoscopy setting characteristics were recorded and their association with an early repeat colonoscopy was determined using an extended Cox proportional hazards regression model.

Results: The cohort consisted of 546467 patients: $55.4 \%$ of the patients were female with a mean age of 61.1 years (95\% confidence interval $[\mathrm{Cl}] 61.1-61.2)$. The cumulative percentage of early repeat colonoscopy after 5.5 years was $33.7 \%$. The rate decreased significantly between 2000 and 2007 (hazard ratio [HR] 0.35, 95\% Cl 0.34-0.36). General surgeons were associated with a higher risk of early repeat colonoscopy than gastroenterologists (HR 1.27, 95\% Cl 1.25-1.28). Endoscopists practising in a nonhospital setting were more likely to perform an early repeat colonoscopy (HR 1.26, 95\% Cl 1.22-1.30) than endoscopists at a hospital.

Interpretation: This study showed that there was overuse of early repeat colonoscopy in more than $30 \%$ of patients who were at low risk for colorectal cancer. The risk decreased significantly between 2000 and 2007 but was still greater than $20 \%$ in 2007 . Our findings can be used to develop targeted educational interventions among subgroups of endoscopists with a higher rate of early repeat colonoscopy.

$\mathrm{P}$ atients with adenoma(s) have a higher risk of metachronous adenoma or colorectal cancer developing, and surveillance colonoscopy is recommended. ${ }^{1-4}$ International guidelines recommend intervals for follow-up colonoscopy based on the most advanced finding at baseline..$^{5-8}$

The number of colonoscopies performed for screening and surveillance is likely to grow in the next decade. Avoiding unnecessary colonoscopy is vital because of limited capacity and costs. Screening and surveillance colonoscopies in excess of guideline recommendations have been reported ${ }^{9-16}$ among patients with a low probability of benefit (e.g., patients over the age of 85 years or with severe comorbidities) or too frequent surveillance colonoscopies among those with low-risk findings (normal or nonadenoma) at baseline colonoscopy. Overuse of colonoscopies undermines the cost-effectiveness of programs for colorectal cancer screening and surveillance, and results in more complications. ${ }^{17,18}$ Overuse may result in prolonged wait times for patients with an appropriate indication for colonoscopy.
Surveys have revealed that physicians recommend that patients who are at low risk for colorectal cancer undergo colonoscopy more frequently than the guidelines recommend. ${ }^{9,10,13,15}$ Studies in the United States reported that more than $20 \%$ of surveillance colonoscopies performed in a Medicare population of patients who were older than 65 years were unnecessary ${ }^{12,19}$ and could have been avoided. ${ }^{12}$

There is a lack of Canadian population-based data on overuse of repeat colonoscopies and associated factors among age groups (50-79 yr) eligible for screening. Our goal was to

Competing interests: See end of article.

This article has been peer reviewed.

Correspondence to: Lawrence Paszat, lawrence@ices.on.ca CMAJ Open 2015. DOI:10.9778/cmajo.20140063 
determine the time to early repeat colonoscopy following a complete colonoscopy with a negative result, among patients aged 50-79 years old in Ontario and the associated factors.

\section{Methods}

\section{Study design}

We conducted a population-based cohort study involving patients who underwent a complete outpatient colonoscopy with a negative result in Ontario between Jan. 1, 2000, and Dec. 31, 2007. All patients were followed up for a maximum of 5.5 years after they were included until the first occurrence of an early repeat colonoscopy, death, colon resection, development of colorectal cancer or inflammatory bowel disease, or the end of follow-up.

\section{Administrative data sources}

Data were obtained from 5 data sources: (1) the Discharge Abstract Database (Canadian Institute for Health Information), which contains standard clinical data for health services provided for each hospital inpatient stay or same-day surgery since 1988. Diagnostic codes recorded in the Discharge Abstract Database are based on the International Classification of Diseases, 9th Revision, from Apr. 1, 1988, to Mar. 31, 2002, and the International Statistical Classification of Diseases and Related Health Problems, 10th Revision from Apr. 1, 2002, onward (Appendix 1, available at www.cmajopen.ca/content /3/2/E244/suppl/DC1). Procedure codes were recorded according to the Canadian Classification of Procedures from Apr. 1, 1988, to Mar. 31, 2002, and the Canadian Classification of Health Interventions from Apr. 1, 2002, onward. (2) The Ontario Health Insurance Plan database, which contains information on claims billed by physicians for reimbursement of services provided to Ontario residents from 1991 onward. (3) The Ontario Cancer Registry, which includes information on all incident cancers diagnosed since 1964. (4) The Registered Persons Database (Ontario Ministry of Health and Long-term Care), which contains demographic information and length of eligibility of all Ontario Health Insurance Plan beneficiaries. (5) The Corporate Providers Database (Institute for Clinical Evaluative Sciences), which contains physician demographic and practice-related information.

\section{Study cohort}

Patients aged 50-79 years who underwent an outpatient complete colonoscopy with a negative result between Jan. 1, 2000, and Dec. 31, 2007, were identified using the Ontario Health Insurance Plan database. The inclusion period ended on Dec. 31,2007 , to allow for 5.5 years of follow-up (the most recent information available in the database was for June 2013). We considered that a patient had a complete colonoscopy if the billing codes indicated that the cecum or the terminal ileum was reached. We considered the colonoscopy as having a negative result if a biopsy or polypectomy was not performed on the same date. We defined this first colonoscopy as the index. Patients who had a diagnosis of colorectal cancer or inflammatory bowel disease, or who had a colonic resection 6 months to
10 years before the index colonoscopy were identified using diagnostic, procedure and billing codes and excluded from the cohort. Patients who had a colonoscopy or colon resection, who were diagnosed with colorectal cancer or inflammatory bowel disease, or who died within 6 months after the index colonoscopy were excluded from the cohort, because these findings may have been related to findings at the index colonoscopy and, therefore, the result for the index colonoscopy could not be considered negative..$^{20}$

\section{Identification of early repeat colonoscopy}

We defined the primary outcome of this study as time to early repeat colonoscopy between 6 months and 5.5 years after the index colonoscopy, which was based on data from physician billing claims. Events occurring during the first 6 months after the index colonoscopy were not captured in the model because these patients were excluded from the cohort. Time was measured from 6 months after the index colonoscopy. Patients were censored at death (last date of contact with the health care system) if they were given a diagnosis of colorectal cancer or inflammatory bowel disease, if they had a colon resection, at the date of termination registration of Ontario health insurance if the patient moved outside Ontario or at 5.5 years after the index colonoscopy.

\section{Covariates}

\section{Patient characteristics}

Patient age, sex, Johns Hopkins aggregated diagnosis groups ${ }^{21}$ (based on diagnosis codes within each of the 32 categories, in the year before the index colonoscopy) and a proxy for socioeconomic status (the median neighbourhood income quintile within the patient's postal code area) were recorded.

\section{Endoscopy characteristics}

Endoscopist characteristics are known to influence the occurrence of an early repeat colonoscopy. ${ }^{19} \mathrm{We}$ recorded the characteristics of the index endoscopist, including sex and specialty (gastroenterologist, general surgeon, internist and other specialties). The main practice location of the endoscopist (hospital-based, nonhospital-based or mixed) was determined based on the setting (hospital or nonhospital) of each colonoscopy billed in the year before the index colonoscopy. Main practice location was defined as mixed if more than 10 colonoscopies per year were performed in both settings. Quality indicators, including colonoscopy volume, polypectomy rate (proportion of colonoscopies with an additional billing code for polypectomy) and completion rate (proportion of colonoscopy with accompanying billing code for intubation of the cecum or terminal ileum), were determined based on physician billing claims in the year before the index colonoscopy.

The colonoscopy was considered hospital-based if the date of the hospital admission record overlapped with the date of the physician billing claim, and it was considered nonhospitalbased if there was no overlapping hospital admission record. Hospital-based setting was subdivided into academic or community hospital based on which hospital institution code was 
used. Consultations by the physician performing the index colonoscopy before this repeat colonoscopy were documented. Cases where no consultations were recorded 12 months before the index colonoscopy were considered open access.

\section{Analysis}

We calculated the descriptive statistics for all covariates included in the study. Risk of early repeat colonoscopy was estimated by the Kaplan-Meier method. To assess the association of patient- and endoscopy-related factors with the hazard of early repeat colonoscopy, we used an extended Cox proportional hazards regression model. ${ }^{22}$ The patient was the unit of analysis and time to this event was the outcome. Patients were censored at time of death, if they were lost to follow-up, if they had a colon resection, if they received a diagnosis of colorectal cancer or inflammatory bowel disease, or at the end of follow-up, depending on which occurred first. Covariates, including patient age, sex, socioeconomic status (categorized per quintiles in urban and rural areas), comorbidity (number of categories with a nonmissing value as a continuous variable), were obtained at the time of the index colonoscopy. In addition, data for calendar year, setting (hospital or nonhospital) of the index colonoscopy, if it was open access, endoscopist specialty

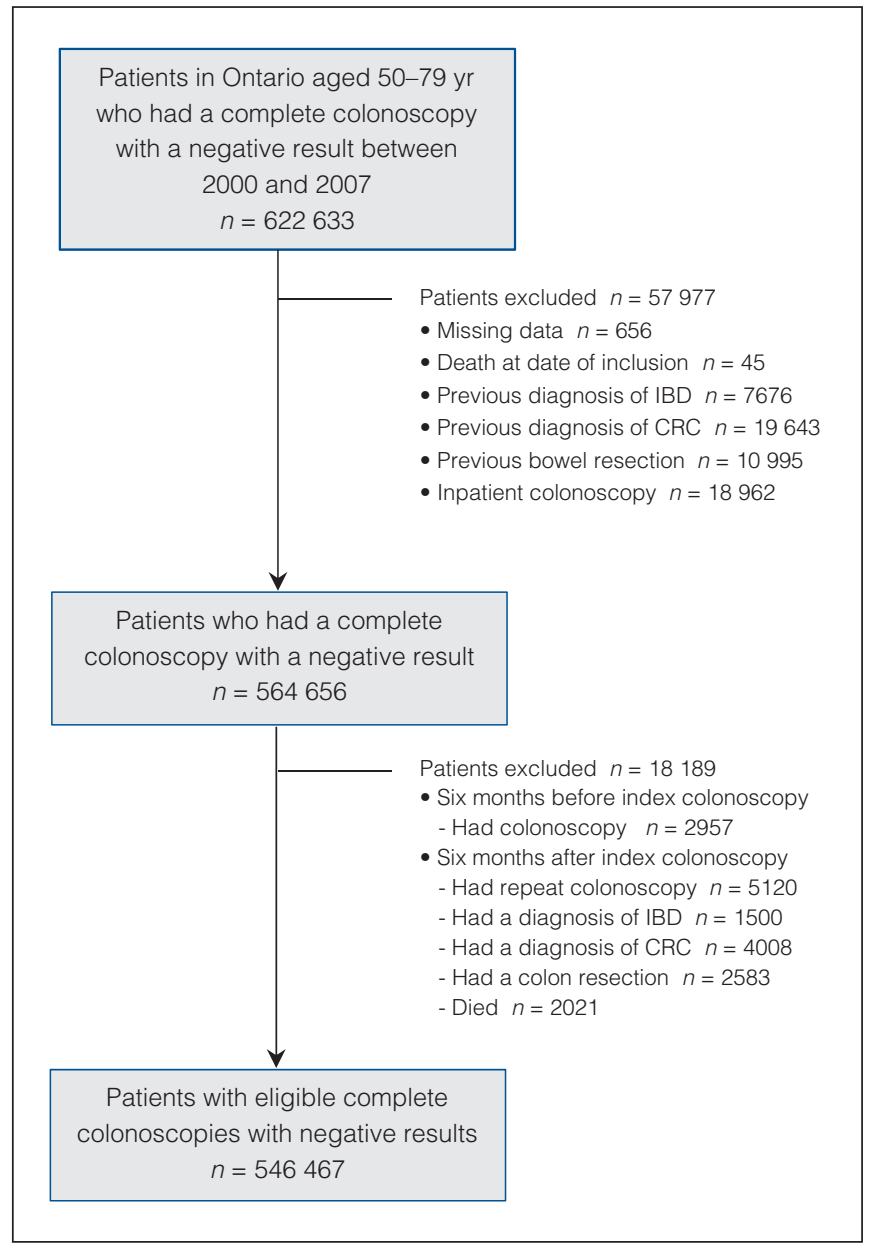

Figure 1: Flow diagram for the selection of participants for the study. $\mathrm{CRC}=$ colorectal cancer, IBD = inflammatory bowel disease. and main practice location of the endoscopist were obtained. Hazard ratios (HRs) with 95\% confidence intervals (95\% CIs) and their associated $p$ values were calculated. Based on the univariate analyses and survival plots, we handled any violation of the proportional hazards assumptions by incorporating interactions with time into the model..$^{23}$ Specifically, we included an interaction with endoscopy-related covariates (setting and open access) and time, where time was categorized as 6-35 months and 36-66 months after index colonoscopy. For the analyses, we used SAS version 9.3 (SAS Institute, Inc., Cary, North Carolina). All statistical tests were 2 -sided, and $p$ values less than 0.05 were considered statistically significant.

\section{Results}

Between 2000 and 2007, 622633 patients aged 50-79 years old had a complete outpatient colonoscopy with a negative result. In total, 57977 patients were excluded because of missing data, a diagnosis of colorectal cancer or inflammatory bowel disease, or a colon resection before the index colonoscopy. Furthermore, patients who had a colonoscopy within 6 months after the index colonoscopy (before $n=2957$, after $n=5120$ ) and those diagnosed with colorectal cancer within 6 months after the index colonoscopy ( $n=10103)$ were also excluded. Therefore, the study cohort included 546467 patients (Figure 1): 55.4\% were female with a mean age of 61.1 years (95\% CI 61.1-61.2). The number of complete colonoscopies with negative results increased by year of inclusion (Table 1).

A total of 1002 endoscopists performed at least 1 index colonoscopy. Most colonoscopies were performed in a hospital setting $(81.0 \%)$ and by general surgeons (53.1\%). Most endoscopists practised only in a hospital $(72.4 \%)$. For the endoscopists who performed the index colonoscopy, the median volume for 1 year was 501 (interquartile range [IQR] 318-716), the completeness rate was 0.97 and the polypectomy rate was 0.22 . Open-access colonoscopies comprised $34.4 \%$.

During the 5.5-year follow-up period, 18602 (3.4\%) of the patients died, $653(0.1 \%)$ were given a diagnosis of inflammatory bowel disease and $519(0.1 \%)$ were given a diagnosis of colorectal cancer or underwent a colon resection $(0.4 \%)$, and were censored. The cumulative percentage of early repeat colonoscopy after 5.5 years based on the Kaplan-Meier analysis was $33.7 \%$. Figure $2 \mathrm{~A}$ shows the cumulative percentage of patients with early repeat colonoscopy by year when index colonoscopy was performed.

Analysis using a Cox proportional hazards regression model showed patient-related factors, including age 65-69 years old, male sex and greater comorbidity were associated with early repeat colonoscopy (Table 2). We used age groups because the relation between age and early repeat colonoscopy was nonlinear. The rate decreased with every subsequent index year from $45.6 \%$ in 2000 to $20.5 \%$ in 2007 (HR 0.35, 95\% CI 0.34-0.36).

Patients who underwent an index colonoscopy performed by a general surgeon had a higher risk (HR 1.27, 95\% CI 1.25-1.28) of early repeat colonoscopy than if the index colonoscopy was performed by a gastroenterologist (Figure 2B). 
An index colonoscopy performed in a nonhospital-based setting was more likely to be repeated than one performed in a hospital (HR 1.05, 95\% CI 1.02-1.07). If the index colonoscopy was performed by an endoscopist practising only in a nonhospital-based setting, patients were more likely to undergo early repeat colonoscopy compared with patients who underwent index colonoscopy performed by an endoscopist practising only in a hospital (HR 1.26, 95\% CI 1.22-1.30). The hazard was similar among endoscopists with a mixed practice and among those with a hospital-based practice (HR 1.00, 95\% CI 0.98-1.01).

Colonoscopy performed in a nonhospital-based setting was more likely to be followed by early repeat colonoscopy (HR $1.05,95 \%$ CI 1.02-1.07) than those performed in a hospitalbased setting. Figure $2 \mathrm{C}$ shows that the association between open-access index colonoscopy and hazard of early repeat colonoscopy was not proportional over time. Within 6-35 months after an index colonoscopy, the risk of an early repeat colonoscopy for a patient with an open-access index colonoscopy was higher (HR 1.24, 95\% CI 1.21-1.26) than the risk for a patient with a nonopen-access index colonoscopy. The risk increased (HR 1.55, 95\% CI 1.51-1.59) during the interval 36-66 months after index colonoscopy.

\section{Interpretation}

\section{Main results}

We found that $33.7 \%$ of the patients in the study cohort had an early repeat colonoscopy within 5.5 years after an index colonoscopy, substantially earlier than recommended by current guidelines. ${ }^{5-7}$ Our data showed a lower hazard ratio with every subsequent year of inclusion. Additionally, endoscopistrelated factors were associated with the probability of early repeat colonoscopy.

\section{Explanation of findings}

One-third of the patients in our cohort had a colonoscopy within 5.5 years of a colonoscopy with a negative result. More aggressive follow-up than once every 10 years in low-risk patients is unlikely to be cost-effective and may even be harmful. ${ }^{17}$ More efficient use of colonoscopy resources is therefore required. ${ }^{24}$ In contrast to the studies involving patients in Medicare populations, ${ }^{12,19}$ we included the entire target population of Ontario who were eligible for screening (50-79 yr), which makes our results generalizable. These data add to the understanding of patient- and endoscopist-related factors associated with early repeat colonoscopy.

The proportion of patients undergoing early repeat colonoscopy decreased from $44 \%$ to $20 \%$ by 2007 . In a US Medicare population, a similar trend was seen with $43 \%$ of patients undergoing early repeat colonoscopy from 2001 to $2003^{11}$ and $23 \%$ from 2008 to $2009 .{ }^{12}$ This reduction over time may suggest greater awareness of current screening guidelines.

A key factor in the patterns of early repeat colonoscopy is the endoscopist's recommendation for the timing of repeat screening. ${ }^{25} \mathrm{We}$ found the risk of early repeat colonoscopy was significantly higher among general surgeons compared
Table 1: Baseline characteristics for patients, physicians and institutions at the patient-level at the time of inclusion

\begin{tabular}{cc}
\hline & No. (\%) of patients \\
Characteristic & $n=546467$
\end{tabular}

Patient

Year of inclusion

\begin{tabular}{rrr}
2000 & 44376 & $(8.1)$ \\
2001 & 52555 & $(9.6)$ \\
2002 & 59036 & $(10.8)$ \\
\hline 2003 & 60007 & $(11.0)$ \\
\hline 2004 & 67536 & $(12.4)$ \\
\hline 2005 & 74140 & $(13.6)$ \\
2006 & 87526 & $(16.0)$ \\
2007 & 101291 & $(18.5)$ \\
Age, yr & & \\
\hline
\end{tabular}

Age, yr

50-54 $139331 \quad(25.5)$

$55-59 \quad 126750 \quad(23.2)$

60-64 $100667 \quad(18.4)$

65-69 $79504 \quad(14.5)$

70-74 $60459 \quad(11.1)$

$75-79 \quad 39756 \quad(7.3)$

Sex

$\begin{array}{lll}\text { Male } & 243659 & (44.6) \\ \text { Female } & 302808 & (55.4)\end{array}$

Comorbidity (JH ADG), median (IQR) 5 (4-6)

Socioeconomic status*

Urban bottom 20th \%。 62218 (11.4)

Urban 60th-80th \%。 79618 (14.6)

Urban 40th-60th \%。 88385 (16.2)

Urban 20th-40th \%。 $102214 \quad(18.7)$

Urban top 20th \%。 $139977 \quad(25.6)$

Rural $\quad 73650 \quad$ (13.5)

Endoscopy

Setting

Community hospital $\quad 365620 \quad$ (66.9)

Academic hospital $\quad 77236 \quad(14.1)$

Nonhospital $103470 \quad(18.9)$

Open access $188175 \quad(34.4)$

Endoscopist

Male $501808 \quad(91.8)$

Specialty

General surgeon 290412

Gastroenterologist $123268 \quad(22.6)$

Internist $122701 \quad(22.5)$

Other $10086 \quad(1.8)$

Main practice location

Hospital $395497 \quad(72.4)$

Private clinic/office $70730 \quad(12.9)$

Mixed $80240 \quad(14.7)$

1-year colonoscopy volume, median (IQR) $501(318-716)$

1-year cecal intubation rate, median (IQR) $0.97(0.94-0.99)$

1-year polyp removal rate, median (IQR) $0.22(0.15-0.29)$

Note: $\mathrm{Cl}=$ confidence interval, $\mathrm{IQR}=$ interquartile range, JH ADG = John Hopkins aggregated diagnosis groups.

${ }^{*}$ No data for socioeconomic status in $456(0.1 \%)$ patients. Socioeconomic status is represented as the median neighbourhood income quintile within the patient's postal code area unless rural.

†Unless otherwise specified. 


\begin{tabular}{|c|c|}
\hline Factor & $\mathrm{HR}(95 \% \mathrm{Cl})$ \\
\hline \multicolumn{2}{|l|}{ Year of inclusion } \\
\hline 2000 & 1 (referent) \\
\hline 2001 & $0.93(0.91-0.95)$ \\
\hline 2002 & $0.85(0.83-0,87)$ \\
\hline 2003 & $0.78(0.76-0.79)$ \\
\hline 2004 & $0.69(0.68-0.71)$ \\
\hline 2005 & $0.62(0.60-0.63)$ \\
\hline 2006 & $0.50(0.49-0.51)$ \\
\hline 2007 & $0.35(0.34-0.36)$ \\
\hline \multicolumn{2}{|l|}{ Age, yr } \\
\hline $50-54$ & 1 (referent) \\
\hline $55-59$ & $1.08(1.07-1.10)$ \\
\hline $60-64$ & $1.17(1.15-1.19)$ \\
\hline $65-69$ & $1.21(1.19-1.22)$ \\
\hline $70-74$ & $1.12(1.10-1.14)$ \\
\hline $75-79$ & $0.91(0.89-0.93)$ \\
\hline \multicolumn{2}{|l|}{ Sex } \\
\hline Male & 1 (referent) \\
\hline Female & $0.90(0.89-0.91)$ \\
\hline Comorbidity (JH ADG) & $1.25(1.23-1.28)$ \\
\hline \multicolumn{2}{|l|}{ Socioeconomic status* } \\
\hline Urban bottom 20th \%。 & 1 (referent) \\
\hline Urban 60th-80th \%。 & $1.24(1.21-1.26)$ \\
\hline Urban 40th-60th \%。 & $1.04(1.02-1.06)$ \\
\hline Urban 20th-40th \%。 & $1.04(1.02-1.05)$ \\
\hline Urban top 20th \%。 & $1.02(1.01-1.04)$ \\
\hline Rural & $1.12(1.10-1.14)$ \\
\hline \multicolumn{2}{|l|}{ Setting } \\
\hline Hospital & 1 (referent) \\
\hline Nonhospital & $1.05(1.02-1.07)$ \\
\hline \multicolumn{2}{|l|}{ Open access < 36 mo } \\
\hline No & 1 (referent) \\
\hline Yes & $1.24(1.21-1.26)$ \\
\hline \multicolumn{2}{|l|}{ Open access $\geq 36 \mathrm{mo}$} \\
\hline No & 1 (referent) \\
\hline Yes & $1.55(1.51-1.59)$ \\
\hline \multicolumn{2}{|l|}{ Specialty } \\
\hline Gastroenterologist & 1 (referent) \\
\hline General surgeon & $1.27(1.25-1.28)$ \\
\hline Internist & $1.05(1.03-1.06)$ \\
\hline Other & $1.21(1.17-1.25)$ \\
\hline \multicolumn{2}{|l|}{ Main practice location } \\
\hline Hospital & 1 (referent) \\
\hline Private clinic/office & $1.26(1.22-1.30)$ \\
\hline Mixed & $1.00(0.98-1.01)$ \\
\hline \multicolumn{2}{|c|}{$\begin{array}{l}\text { Note: } \mathrm{Cl}=\text { confidence interval, } \mathrm{HR}=\text { hazard ratio, JH ADG = John Hopkins } \\
\text { aggregated diagnosis groups. } \\
\text { *Socioeconomic status is presented as the median neighbourhood income } \\
\text { quintile within the patient's postal code area unless rural. }\end{array}$} \\
\hline
\end{tabular}

with gastroenterologists. Patients undergoing a repeat colonoscopy after colorectal surgery for cancer by general surgeons cannot explain this finding. Patient selection based on indication for colonoscopy seems unlikely, because surgeons performed more than $50 \%$ of all colonoscopies included in this study. In keeping with our findings, a survey in the US reported that a significantly larger proportion of surgeons compared with gastroenterologists recommended more frequent repeat colonoscopies in low-risk patients than indicated by the guidelines. ${ }^{15} \mathrm{~A}$ higher hazard of early repeat colonoscopy was observed among endoscopists practising in a nonhospital-based setting only compared with those working in a hospital-based setting or those working in both settings. Factors affecting physician behaviour may have included lack of knowledge of the guideline recommendations, ${ }^{13,15}$ regional differences in practice and financial incentives. ${ }^{15}$

Open-access index colonoscopy was associated with a higher hazard of early repeat colonoscopy. Our findings are similar to a study involving patients undergoing colonoscopy in Spain that reported shortened screening interval as the most common reason for an inappropriate colonoscopy in an open-access endoscopy unit. ${ }^{26}$ This may be explained by inadequate or incorrect communication between the endoscopist and the referring physician responsible for continued care and referral. ${ }^{27}$ Adequate reporting systems for endoscopy are therefore essential, especially because open-access colonoscopies account for a substantial proportion of all colonoscopies. ${ }^{28,29}$ The difference between open- and nonopen-access colonoscopy was not proportional over time. The higher hazard after 3 years of follow-up may indicate that a larger proportion of cases after an open-access colonoscopy had routine scheduling of an early repeat colonoscopy 3-5 years after a colonoscopy with a negative result. We had no reason to believe that independent patients from the same hospital were correlated with respect to their receipt of colonoscopy. Hospital- and physician-level factors could be associated with the hazard of early repeat colonoscopy; therefore, we adjusted for these variables using an extended Cox proportional hazards regression model.

\section{Limitations}

The administrative data had limitations. We could not determine the indication for early repeat colonoscopy (e.g., bowelspecific symptoms). However, substantial complaints (e.g., lower gastrointestinal bleeding) only account for a small proportion of all colonoscopies performed. ${ }^{24}$ The chance of finding important disease is low in those with minor complaints (e.g., change in bowel habits) within 10 years of a complete colonoscopy with a negative result ${ }^{6}{ }^{2}$ and repeating the colonoscopy should be considered inappropriate for these patients. ${ }^{30} \mathrm{We}$ did not have data on family history for the patients included in our cohort. Current guidelines recommend repeating a colonoscopy 5 years after an index colonoscopy with a negative result in patients meeting the criteria for familial colorectal cancer. ${ }^{5}$ However, most early repeat colonoscopies occurred less than 4.5 years after the index colonoscopy, which could still be considered inappropriate as the guidelines recommend a 5 -year surveillance interval. Nonetheless, because we could not identify the patients 
with a family history of colorectal cancer, our data may slightly overestimate the number of early repeat colonoscopies. Two additional reasons for early repeat colonoscopies are inadequate bowel preparation or the resection of a large polyp that was left in situ during the index colonoscopy. ${ }^{5-7}$ In both instances, we would have incorrectly considered the colonoscopy as being

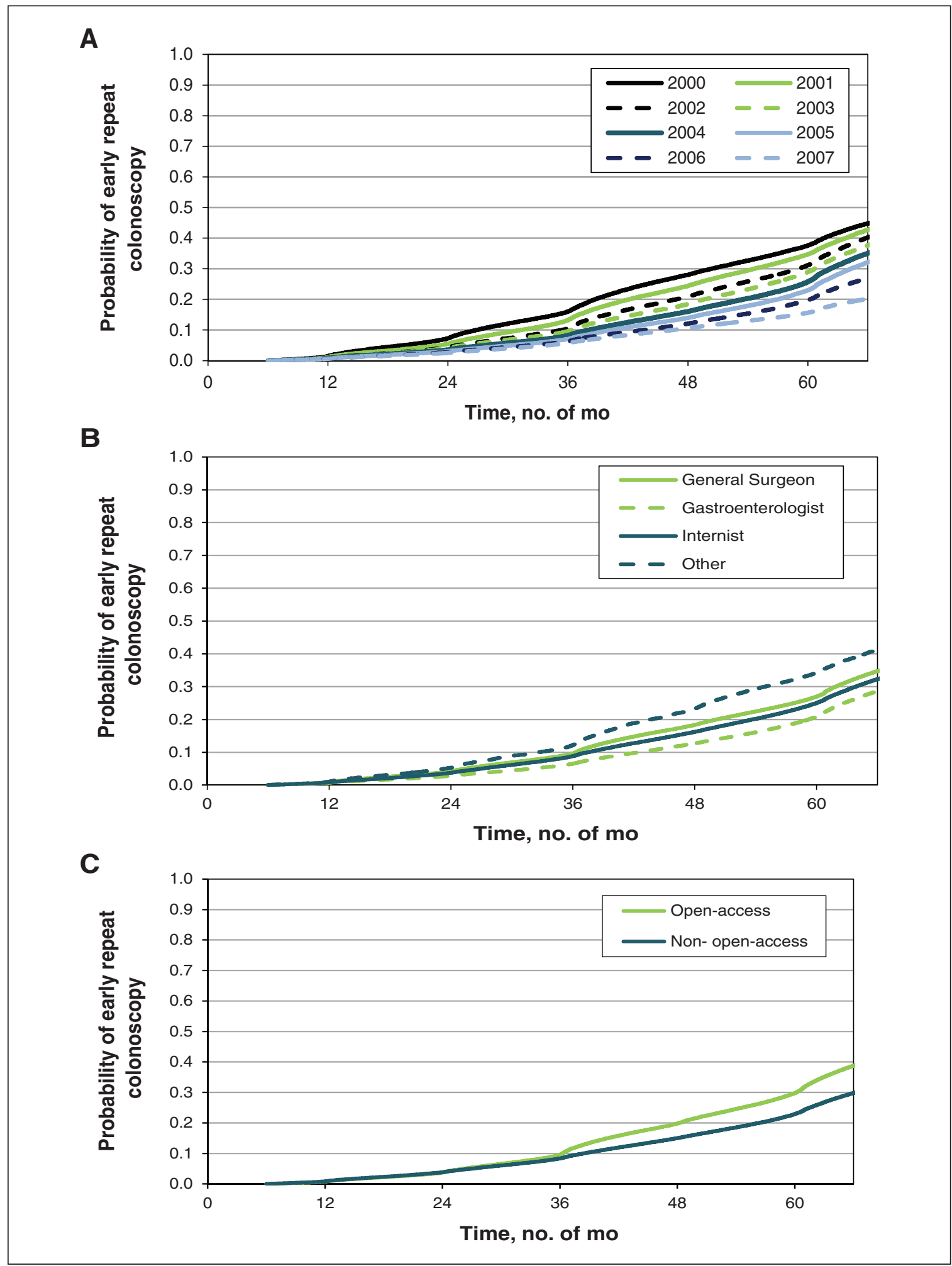

Figure 2: Probability of an early repeat colonoscopy in Ontario by (A) year of index colonoscopy, (B) specialty of the endoscopist and (C) open-access $v$. nonopen-access colonoscopy. Follow-up started 6 months after the index colonoscopy. 
complete and having a negative result based on the administrative data, which did not include data on bowel preparation. To address this potential misclassification, we excluded all patients with a repeat colonoscopy within 6 months after an index colonoscopy. Patients who immigrated within 6 months before the index colonoscopy might have had a colonoscopy outside of Ontario during that time period. However, this would be a small group and likely would not influence our results. Despite these limitations, it is important to highlight that estimates of repeat colonoscopy within 5.5 years are a conservative estimate of actual overuse of colonoscopy, because guidelines recommend a screening interval of 10 years after a negative examination result.

\section{Conclusion}

We showed that there was overuse of repeat colonoscopy after a complete colonoscopy with a negative result in more than $30 \%$ of patients who were at low risk for colorectal cancer. The probability decreased significantly between 2000 and 2007, suggesting more awareness of current screening guidelines. Our findings can be used to develop targeted educational interventions among subgroups of endoscopists with a higher rate of early repeat colonoscopy. In addition, based on the higher hazard of early repeat colonoscopy after an open-access colonoscopy, efforts should be made to improve communication between endoscopists and referring physicians.

\section{References}

1. Singh H, Turner D, Xue L, et al. Risk of developing colorectal cancer following a negative colonoscopy examination: evidence for a 10 -year interval between colonoscopies. FAMA 2006;295:2366-73.

2. Martínez ME, Baron JA, Lieberman DA, et al. A pooled analysis of advanced colorectal neoplasia diagnoses after colonoscopic polypectomy. Gastroenterology 2009;136:832-41.

3. Cottet V, Jooste V, Fournel I, et al. Long-term risk of colorectal cancer after adenoma removal: a population-based cohort study. Gut 2012;61:1180-6.

4. Lieberman DA, Weiss DG, Harford WV, et al. Five-year colon surveillance after screening colonoscopy. Gastroenterology 2007;133:1077-85.

5. Leddin D, Enns R, Hilsden R, et al. Colorectal cancer surveillance after index colonoscopy: guidance from the Canadian Association of Gastroenterology. Can 7 Gastroenterol 2013;27:224-8.

6. Lieberman DA, Rex DK, Winawer SJ, et al. Guidelines for colonoscopy surveillance after screening and polypectomy: a consensus update by the US MultiSociety Task Force on Colorectal Cancer. Gastroenterology 2012;143:844-57.

7. Hassan C, Quintero E, Dumonceau JM, et al. Post-polypectomy colonoscopy surveillance: European Society of Gastrointestinal Endoscopy (ESGE) Guideline. Endoscopy 2013;45:842-51.

8. Atkin WS, Valori R, Kuipers EJ, et al. European guidelines for quality assurance in colorectal cancer screening and diagnosis. First edition - colonoscopic surveillance following adenoma removal. Endoscopy 2012;44(Suppl 3):SE151-63.

9. Boolchand V, Olds G, Singh J, et al. Colorectal screening after polypectomy: a national survey study of primary care physicians. Ann Intern Med 2006;145: 654-9.

10. Schreuders E, Sint Nicolaas J, de Jonge V, et al. The appropriateness of surveillance colonoscopy intervals after polypectomy. Can 7 Gastroenterol 2013; 27:33-8.

11. Singh A, Kuo YF, Goodwin JS. Many patients who undergo surgery for colorectal cancer receive surveillance colonoscopies earlier than recommended by guidelines. Clin Gastroenterol Hepatol 2013;11:65-72 e1.

12. Sheffield KM, Han Y, Kuo YF, et al. Potentially inappropriate screening colonoscopy in Medicare patients: variation by physician and geographic region. 7AMA Intern Med 2013;173:542-50.

13. Saini SD, Nayak RS, Kuhn L, et al. Why don't gastroenterologists follow colon polyp surveillance guidelines?: Results of a national survey. 7 Clin Gastroenterol 2009;43:554-8

14. Schoen RE, Pinsky PF, Weissfeld JL, et al. Utilization of surveillance colonoscopy in community practice. Gastroenterology 2010;138:73-81.
15. Mysliwiec PA, Brown ML, Klabunde CN, et al. Are physicians doing too much colonoscopy? A national survey of colorectal surveillance after polypectomy. Ann Intern Med 2004;141:264-71.

16. Mulder SA, Ouwendijk RJ, van Leerdam ME, et al. A nationwide survey evaluating adherence to guidelines for follow-up after polypectomy or treatment for colorectal cancer. 7 Clin Gastroenterol 2008;42:487-92.

17. Saini SD, Schoenfeld P, Vijan S. Surveillance colonoscopy is cost-effective for patients with adenomas who are at high risk of colorectal cancer. Gastroenterology 2010;138:2292-9, 9 e1.

18. Day LW, Kwon A, Inadomi JM, et al. Adverse events in older patients undergoing colonoscopy: a systematic review and meta-analysis. Gastrointest Endosc 2011;74:885-96

19. Goodwin JS, Singh A, Reddy N, et al. Overuse of screening colonoscopy in the Medicare population. Arch Intern Med 2011;171:1335-43.

20. Rabeneck L, Paszat LF, Saskin R. Endoscopist specialty is associated with incident colorectal cancer after a negative colonoscopy. Clin Gastroenterol Hepatol 2010;8:275-9.

21. Weiner JP. The Johns Hopkins ACG case-mix system version 6.0 release notes Baltimore: The Johns Hopkins University Bloomberg School of Public Health, Health Services Research \& Development Center; 2003.

22. Therneau TM, Grambsch PM. Modelling survival data: extending the Cox model. New York: Springer; 2001

23. Allison PD. Survival analysis using SAS: a practical guide. Cary (NC): SAS Institute 1995.

24. Lieberman DA, Williams JL, Holub JL, et al. Colonoscopy utilization and outcomes 2000 to 2011. Gastrointest Endosc 2014

25. Stock C, Hoffmeister M, Birkner B, et al. Inter-physician variation in follow-up colonoscopies after screening colonoscopy. PLoS ONE 2013;8:e69312.

26. Balaguer F, Llach J, Castells A, et al. The European panel on the appropriateness of gastrointestinal endoscopy guidelines colonoscopy in an open-access endoscopy unit: a prospective study. Aliment Pharmacol Ther 2005;21:609-13.

27. Staff DM, Saeian K, Rochling F, et al. Does open access endoscopy close the door to an adequately informed patient? Gastrointest Endosc 2000;52:212-7.

28. Hadlock S, Rabeneck L, Paszat LF, et al. Open-access colonoscopy in Ontario: associated factors and quality. Can 7 Gastroenterol 2013;27:341-6.

29. Mahajan RJ, Marshall JB. Prevalence of open-access gastrointestinal endoscopy in the United States. Gastrointest Endosc 1997;46:21-6.

30. Sint Nicolaas J, de Jonge V, van Baalen O, et al. Optimal resource allocation in colonoscopy: timing of follow-up colonoscopies in relation to adenoma detection rates. Endoscopy 2013;45:545-52.

Competing interests: Lawrence Paszat received a grant in the form of endowed funds from the Research Committee of the Board of Directors of Cancer Care Ontario.

Affiliations: Institute for Clinical Evaluative Sciences (Hol, Sutradhar, Gu, Baxter, Rabeneck, Tinmouth, Paszat), Toronto, Ont.; Department of Gastroenterology and Hepatology (Hol), Erasmus University Medical Centre, Rotterdam, the Netherlands; Dalla Lana School of Public Health (Sutradhar, Gu), University of Toronto; Department of Surgery and Li Ka Shing Research Institute (Baxter), St. Michael's Hospital; Prevention and Cancer Control (Rabeneck), Cancer Care Ontario; Sunnybrook Health Sciences Centre (Tinmouth, Paszat), Toronto, Ont.

Contributors: Lieke Hol, Rinku Sutradhar, Nancy N. Baxter, Linda Rabeneck, Jill M. Tinmouth, Lawrence F. Paszat contributed substantially to conception and design. Sumei Gu performed the data extraction. Data analyses were performed by Sumei Gu and Lieke Hol. Statistical support was provided by Rinku Sutradhar. The article was drafted by Lieke Hol. All of the authors interpreted the data, critically revised the manuscript for important intellectual content, gave final approval of the version to be published and agreed to act as guarantors of the work.

Funding: This study was supported by the Institute for Clinical Evaluative Sciences (ICES), which is funded by an annual grant from the Ontario Ministry of Health and Long-Term Care (MOHLTC). The opinions, results and conclusions reported in this paper are those of the authors and are independent from the funding sources. No endorsement by ICES or the Ontario MOHLTC is intended or should be inferred. ICES data sets were linked using unique encoded identifiers and analyzed at the Institute for Clinical Evaluative Sciences (ICES).

Supplemental information: For reviewer commetns and the original submission of this manuscript, see www.cmajopen.ca/content/3/2/E244/ suppl/DC1 